\title{
Difference(s) between Male and Female Speakers of Turkish Regarding Politeness Norms
}

\author{
Taher Alavi \\ Islamic Azad University, Branch of Naghadeh, Iran \\ Siamak Moradi \\ Tarbiat Mo'alem University, Iran \\ Mohammad Shahin Taggaddomi \\ Tarbiat Mo'alem University, Iran
}

\begin{abstract}
This study was an attempt to explore the possible differences between male and female speakers of Turkish language as far as politeness norms in speaking was concerned. To achieve this end 20 male and 20 female native speakers of Turkish language were chosen, and their speech was analyzed in different settings. These observations included their speech with different individuals in two settings, namely, formal and informal settings ones. That is to say, in one setting their speech was analyzed when speaking with close friends, and in the other one it was analyzed with more formal individuals, say, their teachers. To explore the differences and similarities, code-switching was selected as a criterion, and the number of code-switchings was counted. These observations were made within 20 sessions. The findings showed a drastic variation in observing politeness norms between male and female speakers of Turkish, especially code-switching from English to Farsi. Besides there were other differences noticed between male and female speakers, for example male speakers used much more taboos, but the most noticeable difference was female speakers' excessive use of code-switching to Farsi.
\end{abstract}

Index Terms — code switching, politeness norms

\section{INTRODUCTION}

Politeness has always been a topic for discussion among people, the topic of most these discussions is about what is polite and what is not. For decades these differences in people's belief of politeness has remained unresolved, and people from various cultural/regional backgrounds have had different beliefs regarding norms of politeness. For example some of them considered indirectness as a symbol and representation of politeness, while others paid much attention to content and expressed it directly.

In dictionary of applied linguistics politeness is defined as "how languages express social distance between speakers and their different role relationships" (Longman dictionary of language teaching and applied linguistics3rd edition In Longman dictionary of language teaching and applied linguistics (3rd edition) politeness is referred to as "the attempt to establish, maintain, and save face during conversation". Different countries have got various norms to show politeness: in China being indirect is a sign of politeness in conversation while indirectness is an indicator of shyness and incapability in western countries.

Traditional theories of politeness (Lakoff1973, Brown \& Levinson 1987, Leech 1983) presented politeness as a phenomenon within linguistic pragmatics and Gricean perspective. In fact they gave priority to speakers' intention, and did not put emphasis on differences between cultures, in other words they hold the idea that various cultures are homogeneous regarding politeness norms. However later approaches (Ellen 2001, Milks 2003, Watts 2003) gave priority to culture, and analyzed different politeness norms considering heterogeneity of cultures, the role of addressee and setting. In fact they believed that "politeness cannot in principle be a matter of using particular linguistic devices/strategies because it is negotiated at the micro level and jointly by the speaker and the addressee" (MarinaTerkourafi, 2003).

Two languages in one person's mind have always been very much important for researchers working in the field of language sciences for many years. In the field of bilingual study, researchers have made so much effort to characterize and formalize dual language knowledge and to identify the cognitive strategies that are invoked in managing and deploying two language systems. For example, Empirical studies have shown that while bilinguals are able to create different phonetic categories from each other, they present phonetic/phonological properties that are not presented in the speech of their monolingual counterparts. Furthermore these results are more likely to be enhanced in the speech of bilinguals who are regularly called on to access and activate their languages at the same time, as in code-switching. Considering individual bilingualism from the morpho-syntax perspective the following research papers all represent the structural properties of bilingual code-switching. Addressing individual bilingualism through the lens of morpho-syntax, 
the research papers assembled herein represent a shared interest in the structural properties of bilingual code-switching. (Almeida Jacqueline Toribio, 2008)

\section{Statement of the Problem}

As mentioned so far politeness norms may vary drastically across cultures, so politeness as a social phenomenon has to be defined in real setting of society. In countries such as Iran, where different cultures co-exist, dealing with politeness differences is more complex. In fact some communities, such as Turkish community has to adapt itself to norms of dominant culture, Farsi. In other words Turkish adults have to make their children aware of Turkish culture as well as Farsi culture.

It is self-evident that cultural gap between Turkish and Farsi is not a small one, so it puts lots of burden on shoulders of parents to get their children acquainted with norms of politeness in both cultures, and this pressure often leads to controversies among female and male parents. In this complex situation children mostly do not understand what they are supposed to do in different situations, and these complexities and paradoxical situations often result in abnormal behaviors on the part of children. In other words they are not context-sensitive enough to behave differently in various situations. It is obvious that abnormal behaviors done by children may embarrass their parents, and this is one of the possible sources of disagreement between female and male parents, because they have quite different attitudes/beliefs toward politeness norms. Another important issue (not dealt with in this paper) is having mother tongue accent while speaking Farsi. Most female parents prefer their children not to have that accent, because mostly it renders their speech deviant. In order to investigate male and female parent's different attitudes/beliefs toward politeness norms, a decision is made to observe their own behavior and manner, while speaking in different settings with different people.

\section{Significance of the Study}

This global economic system has caused an increasing degree of communication among the cultures. Among the cultures communication is problematic since these systems of symbolic meanings are known to one group but unknown to other groups. (Geertz, 1973; Kluckholm\& Kroeber, 1952; Trice \& Beyer, 1992).It is very much important to improve the manager's ability to make communication across cultures and it is very much important to know these differences. (Limaye\& Victor, 1991; Beamer, 1992; Earley, 1987). Whereas in the traditional system of career progress little need for international experience was required. in the future people may require international experience to make leading positions for themselves in their organization (Adler, 1991; Kom, 1989).

Economical and educational system of Iran as a multi-cultural country necessitates Turkish and other language communities to have negotiation with dominant language/culture, and if these communities want to be welcomed in the society they have to change some of their norms and adapt new ones. This process is not easy as it may seem; in fact it is very difficult for a community to avoid its norms/values and adapt new ones. Having new norms/values is not that easy and often leads to complexities. As stated before the need for cross-cultural communication grows every day, and the number of studies done inside Iran as a multi-cultural nation is not that much in quantity. So, the researchers have decided to show how this process leads most Turkish adults to have different and often paradoxical values in different settings.

\section{Null Hypothesis}

There is no difference between male and female speakers of Turkish regarding Politeness norms.

\section{Definition of Terms}

Code-Switching: "a change by a speaker (or writer) from one language or language variety to another one. Codeswitching can take place in a conversation when one speaker uses one language and the other speaker answers in a different language. A person may start speaking one language and then change to another one in the middle of their speech, or sometimes even in the middle of a sentence" (Longman dictionary of language teaching and applied linguistics, $3^{\text {rd }}$ edition).

Politeness: (different definitions has been expressed by different scholars for politeness so far, I just quoted some of them)

a) "How languages express social distance between speakers and their different role relationships" (Longman dictionary of language teaching and applied linguistics, 3rd edition).

b) "Non-prescriptive, true politeness can be thought of as the techniques people use to avoid being offensive, embarrassing, aggressive or presumptuous in conversation" (Cari Sisson, 2007).

c) "Politeness is an attempt by the speaker to preserve the self-esteem, or face, of both the speaker and the hearer" (Brown, P. \& Levinson, S.C 1987).

d) "Politeness is information about the speaker's commitment to particular propositions and their willingness to have this information modified by a hearer" (Brennan \& Ohaeri 1999).

\section{REVIEW OF LITERATURE}

Lots of studies have been done on politeness in recent decades. One of the interesting studies done by Robert Rosenthal (1996) was about politeness strategies expressed through different channels of communication (silent video, speech, full channel video and audio, and transcriptions of speech). In this study he found that politeness strategies were communicated non-linguistically as well as linguistically and that non-linguistic strategy usage was related to social and contextual factors. Differences revealed by Rosenthal between Korean and American politeness were quite interesting. 
For example Koreans' politeness strategies were influenced more by relational setting, whereas Americans' strategies were influenced more by content of the message.

Relevance of politeness to social and contextual factors is self-evident, and in case of Iran, Turkish speakers use lots of strategies to fit to dominant culture. One of the most tangible strategies used by Turkish speakers is code-switching. The interesting point is that Turkish speakers use code-switching even when they are talking to Turkish interlocutors; in other words they insert Farsi words to their Turkish sentences when they are in a formal situation.

Other studies have also been done regarding politeness variations across cultures; an interesting case was reported by Ambady (1996). In his paper he magnified the point that there are some differences between East- Asian societies and America where in the former much importance is given to relational concerns whereas in the latter this importance is diminished. yet in another study Ambady, Koo, Lee, Rosenthal(1996) proposed that in Latin and East-Asian politeness norms it is necessary to eye contact, emotional expressions and tone of voice are carefully attended whereas in European American politeness what is said is more important than how it is said. The situations in Iran do not seem to get in line with these studies, as mentioned earlier Turkish speakers have to insert Farsi words even when speaking Turkish, so that they can be noticed as respectful members of society.

Another interesting research was done by Hall $(1959 ; 1966)$ in his paper, he states that "conceptions of time and of interpersonal proximity are universal in human interaction; these concepts cause variation among different cultures". He also adds that "interpersonal distance is in some cultures relatively small, while in other cultures there are larger degrees of interpersonal distance". Japanese are in the habit of using more ambiguity and indirectness in their speech. Another term for politeness in Japanese culture is linguistic indirection. This is not in line with the nature of politeness theory. Differences in politeness norms apply both in the comparison of Japanese and American speech and occur in the cultures of all societies.). Culture and politeness norms can be investigated from different aspects; for example anthropologists seek norms in various cultures considering universal dimensions, meaning through using constructs universally valid and can be generalized across all human cultures, this approach is called ethic approach. (Bowling Green; Jan 1996). However from social and linguistic perspectives generalizability of cultural values is not much; in other words there are often lots of differences among some cultures that looking for even one commonality seems impossible. It is self-evident that humans are social beings, so politeness norms have always been an important issue throughout history, and people from different regional areas and cultures have always tried different processes to be a part of community, and save their faces; in other words "All humans within all cultures of the world, project a public face, a sense of positive identity and public self-esteem, so throughout social interactions, all individuals try to show they are competent, noticeable, and worthy individuals" (Bowling Green 1996) Since people live in social settings their faces are continuously judged by other members., it is also continuously treated, handled and upheld by others. Other members of society who surround human being in daily communication sometimes engage in interactional support work by means of which they protect and validate speakers' face. But there are settings where members of dominant group do not support individuals, who use different norms, and the result might be quite disappointing for these individuals. In other words there are sets of common interactional events, which are intrinsically likely to generate interpersonal tension or conflict, for instance criticisms, disagreements, asking favors, requesting, saying no to, apologizing, etc.

As Brown and Levinson $(1978,1987)$ suggest "during these face threatening events or moments, we commonly utilize an array of linguistic strategies, or politeness behaviors, in order to mitigate interpersonal conflict. For example, when criticizing someone (an act we know potentially imperils their face), we are likely to linguistically exhibit some polite speech, or when asking for something we are in a face threatening position". It is quite easy to notice in multicultural societies even a simple request potentially puts the people's public face in danger.

Another research done by Brown and Levinson $(1978,1987)$ investigated politeness norms in three entirely unrelated languages; English, Mayan and Tamil (a south Indian, aboriginal language totally unrelated to the Indo-European languages of North India), and they declared that people in every culture share a very broad set of polite linguistic conventions for mitigating the force of speech acts (in essence, that every human language contains expressions of apology, hedges, tag questions, honorifics, etc.) and that these linguistic mechanisms serve the same interactional and social purpose in every language.

For Brown and Levinson there are two categories of politeness ( positive and negative ).In positive politeness the speaker aims to communicate the same impact on the listener, putting much emphasis on their commonalities. However, in negative politeness they are intended to show their respect to the differences between the speaker and listener and let them preserve their autonomy and freedom in being obliged to each other.

In another paper Liliana Sánchez (2011) examines the concept of convergence in some strategies related to case mapping in every day talking of Quechua- Spanish bilinguals. In that language suffixes at the end indicate case markers. The data reveal that speakers of that language those suffixes and Spanish prepositions happen together those mapping strategies converge. This fact (mixing of case markers with Spanish prepositions) is a true indication that the latter one is a case marker not a postposition. Further evidence came from considering this fact that there were no clear differences among the non-oblique and oblique case markers. Samples of case suffix deleting expressions are taken as a mark of instability case marking in code mixing utterances. 
Valerie Hobbs, Ayumi Matsuo and Mark Payne (2010) argue that in the classroom setting also there are many code switching cases between teachers and the students which they employ in their first and target language use. However, few studies have compared the differences between native and non-native teachers most of them have not aimed to consider culture of learning as a variable. In this paper the results obtained how three teachers, one of British and two of Japanese origin, had different applications of classroom language when used in target language vs. the students first language. They came to this understanding that code -switching practices of the teachers are very much affected by the teacher's culture of learning.Field notes and semi- structured interview results revealed that teacher's background and teaching context should be prioritized in language teacher education programs as far as code-switching is concerned.

Brian Hok- Shing Chan (2008) in his paper argue that lexical and functional categories (V, N-D,I,C) have different features regarding code-switching. Functional categories can always determine the order of the elements in codeswitching; however, lexical ones do not possess this feature. This feature is in contrast with the findings of many recent studies which claim that heads are order determining component (e.g. Mahootian, 1993; MacSwan, 1999; Nishimura, 1997; Nishimura and Yoon, 1998. Assuming a "Null Theory" perspective (Mahootian, 1993; MacSwan, 1999), codeswitching data are explained here in terms of existing syntactic apparatus which also governs monolingual syntax. It is proposed that word order between lexical categories and their complements are determined by head parameter instead of feature strength as an intrinsic property of the lexical heads. Nonetheless, head-complement order is inherently specified in functional categories. On this account, prepositions are functional heads instead of lexical heads.

Pondering upon the lack of explanatory deepness in the previous studies regarding bilingual code-switching, Jim Hlavac (2006) examines the distribution and usefulness of the aforesaid techniques in English and Croatian. It should be added that the corpus includes 100 Croatian and English bilinguals' recordings. Very high rates of co-occurrence are reported to be evident in English and Croatian, however; lack of correspondence is evident in poly functional forms. It goes without saying that poly functional patterns are single forms for accomplishing various functions.

His- Yau Su (2002) employs a combination of qualitative and quantitative methods for examining a Taiwanese bilingual to see his code-switching styles in face-threatening telephone conversations. The study shows that the used code-switching styles are under the influence of the speakers' cultural and ethnic background. This study also illustrates that, while on the sequential level code-switching serves to organize the internal structure of the conversations, on the interactional level it can be used simultaneously with other linguistic strategies to negotiate interpersonal relationships in a face-threatening situation and is but one among a variety of resources circulating in the society available to bilingual speakers in performing various tasks in their daily interactions. This study further demonstrates how codeswitching should be understood alongside notions such as footing (Goffman, 1981) and politeness (Brown and Levinson, 1987), arguing that an adequate study of interactional code-switching should be situated within a larger study of linguistic practices and social interaction.

Peter Auer (2005), discusses the processes of social identity construction accomplished via code-switching and codemixing techniques. The researcher states that the employment of extra linguistic tools is typical among bilingual language users. He also claims that bilinguals use a combination of various techniques to build social identity under different circumstances.

\section{METHOD}

I tried to observe 20 male and 20 female native Turkish speakers in a city where the only language for communication was Turkish, and I observed them in different settings. In order to observe females in informal setting I used the cameras of an institute to record their voice before the teacher's arrival for about 15 minutes, and I did not attend to in their classes as an observer, because my presence as a male might cause them to behave formally. In order to observe them in formal setting I recorded their voice while their teacher was in class, and 15 minutes at the beginning of the class we did our project. In both settings (formal and informal) the only language for communication was Turkish. It should be clarified that in formal setting the medium of communication was Turkish too, because all three classes were at the beginning level and the teacher had to initiate the class in Turkish in order to warm them up. As mentioned so far, I used three beginning level classes to observe females, and I used three different classes just to create age differences. Class number 1 included 7 female students with ages ranging from 11 to 16, in class number 2 there were 8 females their ages ranging from 20 and 28, and finally class number 3 consisted of 5 female students their ages ranging from 26 to 35. As for male classes we tried to make the situation very much similar to the females'. The only difference was that there were only two classes instead of three. In the first class there were 12 students their ages ranging from 12 to 17, and the second class consisted of 8 students their ages ranging was from 19 and 27.Having observed these classes for 9 sessions, the total numbers of code-switching to Farsi was counted, while subjects were speaking Turkish, and a significant difference was found between males and females. The spss calculated results are given in the following table.

\section{RESULTS}




\begin{tabular}{|l|l|l|l|l|l|}
\hline & Value & df & Asymp. Sig. (2-sided) & Exact Sig. (2-sided) & Exact Sig. (1-sided) \\
\hline Pearson Chi-Square & $5.885^{\mathrm{a}}$ & 1 & .015 & & \\
Continuity Correction & 4.270 & 1 & .039 & & \\
Likelihood Ratio & 4.837 & 1 & .028 & .026 & \\
Fisher's Exact Test & & & .026 & \\
Linear-by-Linear Association & 5.841 & 1 & .016 & & \\
N of Valid Cases & 134 & & & & \\
\hline
\end{tabular}

\section{DisCUSSION}

As stated above in the introduction part, politeness norms have been investigated from two different perspectives. One was traditional view (Lakoff 1973, Brown and Levins-on 1987, Leech 1983) that considered speakers' intention as the most important criterion of politeness; in other words this view did not put emphasis on differences between cultures. However later approaches (Ellen 2001, Milks 2003, WATS 2003) gave priority to cultural differences regarding politeness norms. According to the results of present study, the second approach seems more plausible, because the results showed that Turkish female speakers considered code-switching as a politeness norm, while female speakers of other languages/cultures might not.

The other issue dealt with in this paper was differences between male and female speakers of Turkish regarding politeness norms. As shown in the result section there was a significant difference between males and females regarding code-switching's according to the findings of this paper it can be claimed that the traditional view (Lakooff 1973, Brown and Levinson 1987, Leech 1983) does not make sense; in other words speakers' intention is not the most important criterion regarding politeness. It seems that politeness norms should be considered as a mixture of speakers' intention, culture/language and gender; to put in another way the results of this article were more in line with more recent approaches (Ellen 2001, Milks 2003, Wats 2003) which considered cultural differences as a dominant criterion in case of politeness norms.

\section{REFERENCES}

[1] Bowling green. (1996). Politeness as a Universal Variable in Cross-cultural Managerial Communication; International Journal of Organizational Analysis.

[2] Brennan, S.E, \&Ohaeri, J.O. (1999). Why do Electronic Conversation Seem Less Polite? International Joint Conference on Work Activities.

[3] Brown, P. \&Levinson, S.C. (1987).Politeness: Some universals in Language Usage. Cambridge and New York: Cambridge University Press.

[4] CariSisson. (2007). Cross-Cultural Politeness and Media. Computer Mediated Communication Project.

[5] Geertz. (1973). The Interpretation of Cultures. Basic Books 2000 paperback: ISBN No-465-09719-7.

[6] Harrison M. Trice and Janic M. Beyer, paperback. (1992). Pearson Education ISBN-100131914383.

[7] Kluckholm and Kroeber. (1952). Culture, a Critical Review of Concepts and Definitions, Cambridge.

[8] Lakoff. (1973). Language and Woman's Place. Language in Society. Vol. 2, No. 1, pp. 45-80

[9] Leech. G. (1983). Principles of Pragmatic. Walking and Talking Victims of Strangulation: is there a new epidemic? London, Longman.

[10] Marina Terkourafi. (2003). Three levels in Politeness Theory and Practice, British school at Athens, Greece\& University of Cambridge, U.K.

[11] Nancy J. Adler. (1991). International Dimensions of Organizational Behavior.

[12] Richards J. Watts. (2003). Another Term for Politeness is "Linguistic Indirection", University Bern Switzerland.

[13] Robert Rosenthal, Ambady, Koo, Lee. (1996). Linguistic and Nonlinguistic Politeness in two cultures. Journal of Personality and Social Psychology. Vo. 70, No. 5,996-1011.

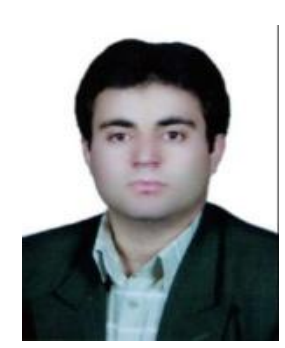

Taher Alavi was born in Nagade, West Azerbaijan , Iran ( September 23 , 1975 ). He has got M.A in TEFL /TESL from the university of Allame abatabaee, Tehran, Iran. He got his B.A in the same field from Shiraz University, Iran. He has been teaching English in different local universities and language institutes since 2000. He has been offering different courses in the field of Language teaching methodology, and language testing for language students. At the present time he is the SUPERVISOR in his own language Institute, and teaching English for the advanced level students. So far he has developed a book which was published in Germany.

ON THE EFFECT OF THEMATIZATION ON THE COMPREHENSION OF SENTENCES WITH

DIFFERENT VERB CATEGORIES AT INTERMEDIATE LEVEL. (Germany, VDM, 2011)
He has been able to get one of his papers be published in the journal of JLTR in January 2012 and

published another one in the journal of TPLS. 


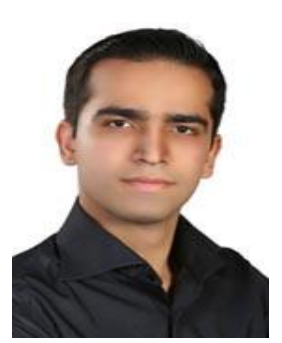

Siamak Moradi was born in 1987, Ahar, Iran. He received his B.A. in English literature in 2009 from Payam-noor University. Now, he is studying M.A. in TEFL at Tarbiat Mo'allem University, Tehran, Iran. He has been teaching English for almost two years in different language institutes, including Zaban Sara and Alavi Sulduz language institute, both located in Nagadeh, West Azerbaijan, Iran. His main interests are post method pedagogy and reflective teaching. And recently he is trying anxiety reducing procedures in his classes. He also published a paper in Theory and Practice in Language Studies, (2011).

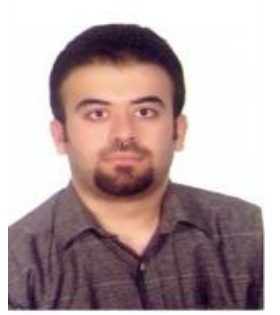

Mohammad Shahin Taghaddomi received his B.A. in English Language and Literature. He is currently doing his M.A. in TEFL at TarbiatMo'allem University, Tehran, Iran. He has been teaching English for more than four years; recently, he has been teaching at Zaban Sara Language center (Sanandaj Branch). His areas of interest are teaching Methodology, Task-based Language Teaching, Teacher Education, and Reflective Language Teaching. 